which is higher than the observed in the Spanish cohort but it is within the EULAR range. The frequency of Raynaud's phenomenon, cutaneous vasculitis, lymphadenopathy, splenomegaly and pericarditis were similar to those observed both in the Spanish national group and EULAR cohort.

Abstract AB0562 - Table 1. Exocrine Gland Disease

\begin{tabular}{|l|c|c|c|}
\hline \multicolumn{1}{|c|}{ EXOCRINE GLAND DISEASE } & $\begin{array}{c}\text { No PATIENTS } \\
\text { AFFETTED }\end{array}$ & PERCENTAGE (\%) & $\begin{array}{c}\text { S SOOGREN-SER } \\
\text { PRECENAGE } \%)\end{array}$ \\
\hline Dry eye & 96 & 91 & 94.51 \\
\hline$-\quad$ Keratoconjunctivitis sicca & 43 & 40.6 & 91.99 \\
\hline Dry mouth & 74 & 69.8 & 94.05 \\
- Recurrent parotiditis & 16 & 15 & 35.24 \\
- Salivary gland enlargement & 13 & 12.3 & 4.35 \\
\hline Xerosis & 27 & 25 & 72.31 \\
\hline Atrophic chronic gastritis & 15 & 14 & 4.81 \\
\hline Upper respiratory tract dryness & 14 & 12.3 & 15.33 \\
\hline Vaginal dryness / dyspareunia & 12 & 11.3 & 48.97 \\
\hline
\end{tabular}

Abstract AB0562 - Table 2. Extraglandular Disease

\begin{tabular}{|c|c|c|c|c|}
\hline $\begin{array}{l}\text { EXTRAGLANDULAR } \\
\text { DISEASE }\end{array}$ & $\begin{array}{l}\text { № PATIENTS } \\
\text { AFFECTED }\end{array}$ & PERCENTAGE (\%) & $\begin{array}{l}\text { SJJ̈GREN-SER } \\
\text { PERCENTAGE (\%) }\end{array}$ & $\begin{array}{c}\text { EULAR } \\
\text { PERCENTAGE (\%) }\end{array}$ \\
\hline Chronic fatigue & 54 & 50.9 & 63.16 & $50-75$ \\
\hline $\begin{array}{l}\text { Arthralgia } \\
\text { Inflammatory arthritis }\end{array}$ & $\begin{array}{l}43 \\
35\end{array}$ & $\begin{array}{l}40.6 \\
33\end{array}$ & $\begin{array}{r}34.55 \\
2.97 \\
14.65\end{array}$ & $\begin{array}{c}53 \\
15-30 \\
22-33\end{array}$ \\
\hline $\begin{array}{l}\text { Fibromyalgia } \\
\text { Depression }\end{array}$ & 3 & & & $\begin{array}{c}22-33 \\
40\end{array}$ \\
\hline $\begin{array}{l}\text { Depression } \\
\text { Raynaud's phenomenon }\end{array}$ & $\frac{26}{22}$ & $\begin{array}{l}24.5 \\
20.8\end{array}$ & 21.05 & $18-37$ \\
\hline Intersticial lung disease (ILD) & 16 & 15.1 & 6.64 & 5 \\
\hline Cutaneous vasculitis & 15 & 142 & 9.15 & 10-15 \\
\hline Peripheral neuropathy & 12 & 11.3 & 8.92 & 5-10 \\
\hline Lymphoma & 5 & 4.7 & 1.18 & $5-10$ \\
\hline Renal disease & 2 & 1.8 & 1.83 & $<5$ \\
\hline
\end{tabular}

Conclusions: Extraglandular disease in SS, although less frequent than sicca symptoms, have a special relevance when it comes to patient management. In our study the frequency of both glandular and extraglandular disease was similar to the observed in Sjögren-SER and EULAR groups although there were some differences. Fibromyalgia was less frequent in our group, whereas interstitial lung disease and peripheral neuropathy were more prevalent

Disclosure of Interest: None declared

DOI: 10.1136/annrheumdis-2018-eular.5400

\section{AB0563 METABOLIC SYNDROME PREDICTS NEW DAMAGE IN SYSTEMIC LUPUS ERYTHEMATOSUS PATIENTS}

C. Reátegui-Sokolova ${ }^{1}$, R.V. Gamboa-Cárdenas ${ }^{1}$, M. Medina ${ }^{1}$, F. Zevallos ${ }^{1}$, C. Elera-Fitzcarrald ${ }^{1,2}$, V.R. Pimentel-Quiroz ${ }^{1}$, J.M. Cucho-Venegas ${ }^{1}$, J.L. AlfaroLozano $^{1}$, Z.J. Rodriguez-Bellido ${ }^{1}$, C.A. Pastor-Asurza' ${ }^{1}$, R.A. Perich-Campos ${ }^{1}$, G. S. Alarcón ${ }^{3}$, M.F. Ugarte Gil ${ }^{1,2},{ }^{1}$ Rheumatology, Hospital Guillermo Almenara Irigoyen; ${ }^{2}$ Universidad Científica del Sur, Lima, Peru; ${ }^{3}$ School of Medicine, University of Alabama, Alabama, USA

Background: The metabolic syndrome (MetS) is a complex of interrelated risk factors for the occurrence of cardiovascular disease and diabetes, and it is now both a public health and a clinical problem(. ${ }^{1}$ The MetS has also been reported to be associated with new organ damage, vascular events and mortality in Systemic Lupus Erythematosus (SLE) patients. ${ }^{2}$

Objectives: To determine whether the MetS predicts damage accrual in SLE patients.

Methods: This prospective study was conducted in a cohort of consecutive SLE patients seen since 2012 at one single institution. Patients had a baseline visit and follow-up visits every 6 months. Patients with $\geq 2$ visits were included. Evaluations included interview, medical records review, physical examination and laboratory tests. Damage accrual was ascertained with the SLICC/ACR damage index (SDI) and disease activity with the SLEDAI. The MetS was defined if the patient fulfilled 3 of 5 criteria according to Alberti et al. ${ }^{1}$ Survival univariable and multivariable Cox-regression models were carried out to determine the risk of developing new damage. The multivariable model was adjusted for age at diagnosis, disease duration, socioeconomic status, SLEDAI, baseline SDI, the Charlson Comorbidity Index, baseline use of prednisone (PDN), antimalarials and immunosuppressive drugs.

Results: Two hundred and forty-nine patients were evaluated; 232 were females and 17 males. Their mean (SD) age at diagnosis was 35.8 (13.1) years; nearly all patients were mestizo. Disease duration was $7.4(6.6)$ years. The SLEDAI was 5.2 (4.3) and the SDI 0.9 (1.3). The average daily dose of PDN was $7.3(6.4) \mathrm{mg} / \mathrm{d}$ and the time of exposure to PDN was 6.9 (6.2) years. One hundred and eight patients (43.4\%) had MetS at baseline. During follow-up, 116 (46.6\%) patients accrued at least one new point in the SDI damage index. In multivariable analyses, the presence of MetS was a predictor of development of new damage; with a Hazard Ratio (HR) 1.54 (1.05-2.26); p:<0.029.

Conclusions: The presence of MetS predicts the development of new damage in SLE patients, despite of other well-known risk factors for such occurrence.

\section{REFERENCES :}

[1] Alberti KGMM, Eckel RH, Grundy SM, Zimmet PZ, Cleeman JI, Donato $\mathrm{KA}$, et al. Harmonizing the metabolic syndrome: a joint interim statement of the International Diabetes Federation Task Force on Epidemiology and Prevention; National Heart, Lung, and Blood Institute; American Hear Association; World Heart Federation; International Atherosclerosis Society and International Association for the Study of Obesity. Circulation [Internet]. 2009 Oct 20 [cited 2018 Jan 27];120(16):1640-5. Available from: http://www.ncbi.nlm.nih.gov/pubmed/19805654

[2] Mok CC, Tse SM, Chan KL, Ho LY. Effect of the metabolic syndrome on organ damage and mortality in patients with systemic lupus erythematosus: a longitudinal analysis. Clin Exp Rheumatol [Internet]. 2017 Oct 18 [cited 2018 Jan 27]; Available from: http://www.ncbi.nlm.nih.gov/pubmed/ 29148424

Disclosure of Interest: None declared

DOI: 10.1136/annrheumdis-2018-eular.6106

\section{AB0564 DRY SYNDROME IN RA PATIENTS. COMPARISON WITH SJÖGREN'S SYNDROME PATIENTS}

D. Peiteado ${ }^{1}$, G. Bonilla ${ }^{1}$, R. Montejano ${ }^{2}$, A. Boto ${ }^{2}$, A. Del Hierro ${ }^{2}$ I. Monjo ${ }^{1}$, C. Plasencia ${ }^{1}$, A. Balsa ${ }^{1} .{ }^{1}$ Rheumatology, ${ }^{2}$ Ophthalmology, Hospital Universitario la Paz, Madrid, Spain

Objectives: The aim of the study is to analyse the clinical characteristics of Rheu matoid Arthritis (RA) patients and dry syndrome, and to compare with primary Sjögren's syndrome (PSS) patients.

Methods: Patients with RA and dry syndrome derived from Rheumatology Clinic to Cornea Unit were evaluated. According to symptoms and ophthalmological examination, patients were classified as high or low probability of Sjögren Syndrome (SS). Clinical and laboratory assessments included sex, age and smoking habit, DAS28, erythrocyte sedimentation rate (ESR), C-reactive protein (CRP) rheumatoid factor (RF), anti-citrullinated peptide antibodies (ACPA), antinuclear antibodies (ANA), anti Ro, anti La and presence of other extraarticular symptoms. In addition, the ophthalmological examination data (Ocular Staining Score [OSS] and Schirmer test), salivary gland scintigraphy (SGS) and salivary gland biopsy (biopsy) were analysed. The percentage of patients who would be classified according to the criteria of the Revised American-European Consensus Group (AECG) 2002, NIH-funded Sjögren's International Collaborative Clinical Alliance (SICCA) 2012 criteria and ACR/EULAR 2016 criteria is evaluated. RA patients with high probability of SS are compared with SSP patients. Statistics analysis was made by mean $\pm S D$, and comparison was made by t- Student test (quantitative parameters) and non parametric test (qualitative) $(\mathrm{p}<0.05)$.

Results: 24 RA with dry syndrome were included. $71 \%$ were women and the mean age was $64 \pm 14$ years. The disease duration was $17 \pm 12$ years. All patients had ocular manifestations, $2 / 3$ oral manifestations, and $17 \%$ other extra-articular manifestations. According to DAS28, 33\% of the patients were in clinical remis sion, $33 \%$ in high activity, and the others in low-moderate activity. 17 patients (71\%), 19 (86\%) and 5 (21\%) were positive (+) for RF, ACPA and ANA, respectively. One patient had Anti Ro +and another anti La +. The mean OSS was 4.2 $( \pm 3.1)$ and the average of Schirmer was $10( \pm 11)$. In relation to other tests: 7 patients had a biopsy performed ( 2 positive [29\%]), 5 patients had GGS ( 2 positive [40\%]).

17 of the 24 RA patients (71\%) were considered "high probability Sjögren's Syndrome" (SS and AR). These patients were compared with the PSS group (see table 1), showing differences in immunological parameters, sex, age and in the\% that fulfilled the classification criteria. No significant differences were found in the ophthalmological examinations or the acute phase reactants.

Abstract AB0564 - Table 1

\begin{tabular}{|c|c|c|}
\hline & SS and RA (n 17) & PSS (n 16) \\
\hline OSS (mean $\pm s d)$ & $6 \pm 2$ & $6.4 \pm 2.6$ \\
\hline SCHIRMER (mean \pm sd) & $6.8 \pm 8.3$ & $4 \pm 4$ \\
\hline ANA & $4(23 \%)$ & $16(100 \%)^{\star \star}$ \\
\hline Anti RO/ANTI LA & $1(6 \%) / 1(6 \%)$ & $15(94 \%) / 13(81 \%)^{* *}$ \\
\hline ACPA (media $\pm D S)$ & $667 \pm 866$ & $0.1 \pm 0.3^{* *}$ \\
\hline Gender $(\delta / q)$ & $6 / 11$ & $0 / 16^{*}$ \\
\hline AECG 2002 criteria & $4(23 \%)$ & $15(94 \%)$ ** \\
\hline $\begin{array}{l}\text { N (\%) } \\
\text { ACR } 2012 \text { criteria }\end{array}$ & $2(12 \%)$ & $15(94 \%)$ ** \\
\hline $\begin{array}{l}\text { N (\%) } \\
\text { ACR/EULAR } 2016 \text { criteria } \\
N(\%)\end{array}$ & $3(18 \%)$ & $16(100 \%)$ ** \\
\hline Age & $66.7 \pm 11.6$ & $56 \pm 17.2^{*}$ \\
\hline
\end{tabular}

${ }^{*} p<0.05 ;{ }^{* *} p<0.01$ 